\title{
CONTROL OF DESIGNED TARGET SEEKER, USED IN SELF-GUIDED ANTI-AIRCRAFT MISSILES, BY EMPLOYING MOTORS WITH A CONSTANT TORQUE
}

\author{
Daniel Gapiński, Konrad Stefański \\ Faculty of Mechatronics and Machinery Design, Kielce University of Technology, \\ al. 1000-lecia P.P 7, 25-314 Kielce, Poland \\ E-mail: tu_daniel_kielce@wp.pl (correrspondingauthor); stefan5@interia.pl
}

Received 11 November 2013; accepted 28 February 2014

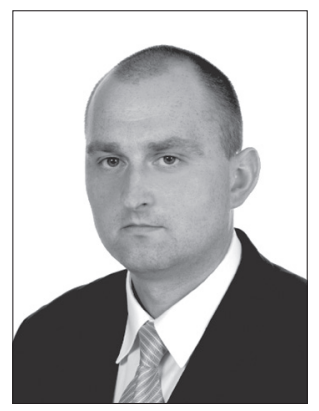

Daniel GAPIŃSKI, $M S c$, Eng.

Education: 2000 to 2005 -MSc (Eng.) degree in Mechanics and Machine Building, Kielce University of Technology, Faculty of Mechatronics and Machine Building. Specialization: Armament Technologies. 2005 to 2006 - military rank: Lieutenant, Polish Air Force Academy in Dęblin.

Affiliations and functions: 2012 to present - Assistant Lecturer, Kielce University of Technology, Department of Computing and Armament.

Research interests: computer programming, dynamics and control of optical scanning seekers in anti-aircraf missiles.

Publications: author of 1 scientific article and co-author of 4 scientific articles. Author and co-author of 5 conference papers.

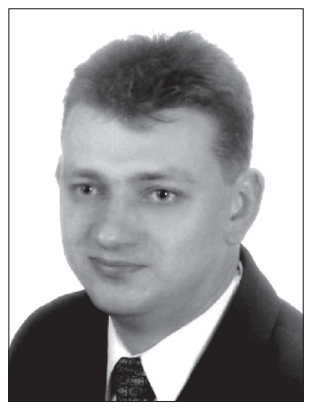

Konrad STEFAŃSKI, PhD, Eng.

Education: 1996 to 2000 - MSc (Eng.) degree in Civil Engineering, Kielce University of Technology, Faculty of Civil Engineering. 2010: PhD degree in Mechanics, Military University of Technology in Warsaw, Faculty of Mechatronics, Specialization: Construction and Control of Flying Object.

Affiliations and functions: 2003 to 2011- Assistant Lecturer, Kielce University of Technology, Department of Vehicles and Mechanical Equipment. 2011 to present - Assistant Professor, Kielce University of Technology, Department of Computing and Armament. Research interest: control of mechatronics devices with an emphasis on quality control. Publications: author of 3 scientific articles and co-author of 25 scientific articles. Author and co-author of 27 conference papers.

\begin{abstract}
This paper presents the results of research on control of a designed target seeker (Gapiński, D. 2008), which was carried out using of the so-called "signum" function. The technical feasibility of controlling the seeker axis in the phase of searching the air space with the simultaneous consideration of the process of scanning through the optoelectronic system of the head was verified. The numerical analysis of the device dynamics was presented and the analysis of the possibility of practical application previously mentioned method for the control of the designed seeker was conducted. The results are presented in a graphical form as well.
\end{abstract}

Keywords: optical scanning and tracking head, phase trajectories, control deviations, gyroscope, target.

\section{Introduction}

Structural solutions for optical scanning heads are being continuously improved by the biggest armaments companies in the world, as proven by most recent European and American patents published in the years 2006-2012 (Bar- enz et al. 2012; Rueger, Zoz 2012; Anderson et al. 2010). It emerges among others from the dynamic technological development of air attack means. On present battlefields, the opponent has the equipment enabling to carry out air combat missions with greater and greater precision and 
with greater velocities. Furthermore, for several years, disruptions caused by the target have been applied in order to mislead the seeker optical system (ostensible targets). The paper presents the design of such a device, while its innovation, structure and principles of operation were presented in the patent specification (Gapiński 2008). The paper discusses the possibility of controlling the designed scanning and tracking head with the use of electric motors with a constant torque, whose rotary velocity directions are specified according to the method based on the so called function "singnum", and described among others in (Osiecki, Stefański 2003, 2008; Stefański 2004).

\section{Design of the scanning and tracking head}

Figure 1 presents a 3D visualisation of the designed head. A detailed description of the design, including the list of parts, is included in the patent solution (Gapiński 2008). The main components of the seeker include: complete spherically-shaped outer housing (1), complete spherically-shaped inner housing (2), as well as gyroscope rotor together with the optoelectronic system (3). The inner and outer housing constitute the Cardan joint, due to which the rotor, together with the optoelectronic system, is separated from the missile base (maintains the set direction in space), and it is possible to precisely control the seeker axis. The designed head has two modes of operation. In the first mode, the head searches the air space in order to detect and locate a flying object, whereas in the second mode, it tracks the located target. In this article, the first mode of operation is analysed, during which the control of the head axis with the "signum" function was performed.

The moments of inertia of individual elements of the seeker have been calculated in relation to respective axes of the adopted systems of coordinates (Fig. 2). The beginnings of all such systems overlap and are at the intersection of the axis of rotation of the outer housing with the axis of rotation of the inner housing of the head. Maximum torques of individual motors, controlling the outer and inner housing, have been determined based on the previous analysis of the seeker dynamics.

The process of scanning the air space by the optoelectronic system of the device in its first mode of operation is shown in figure 3 . The figure presents the surface scanned by the seeker which is $3000[\mathrm{~m}]$ away from the firing position. The scanning time amounts to 0.178 [s].

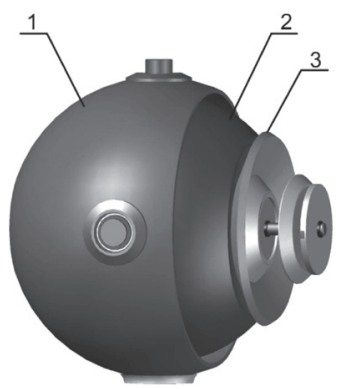

Fig. 1. 3D visualisation of the designed target seeker

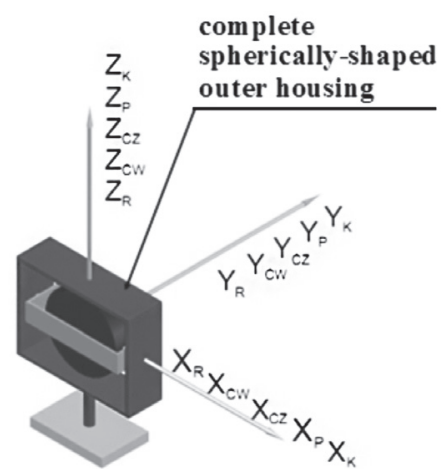

a)

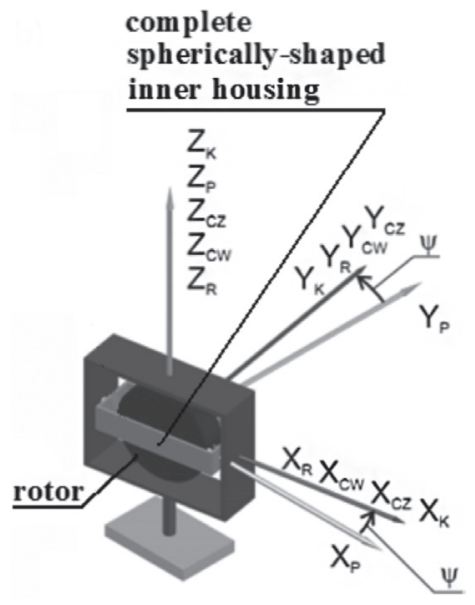

b)

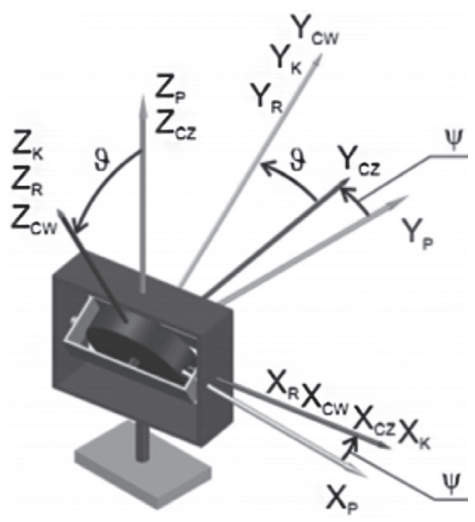

c)

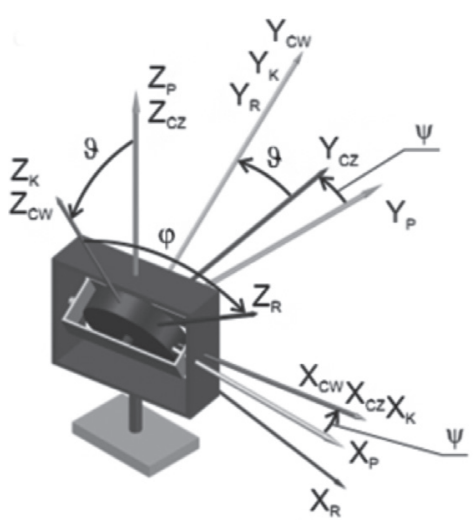

d)

Fig. 2. The diagram of the head, including the adopted systems of coordinates 


\section{Mathematical model}

Figure 3 presents the diagram of the gyroscope of the designed scanning and tracking head, including the adopted systems of coordinates and angles of rotation of those systems in relation to each other.

The following systems of coordinates have been marked on figure 2:

$O X_{K} Y_{K} Z_{K}$ - system of coordinates connected with the set direction in space which should be maintained by the scanning and tracking head;

$O X_{P} Y_{P} Z_{P}$ - mobile coordinate system connected with the missile on which the head is mounted;

$O X_{C Z} Y_{C Z} Z_{C Z}$ - mobile coordinate system connected with the gyroscope outer housing;

$O X_{C Z} Y_{C Z} Z_{C Z}$ - mobile coordinate system connected with the gyroscope outer housing;

$O X_{R} Y_{R} Z_{R}-$ mobile coordinate system connected with the rotor.

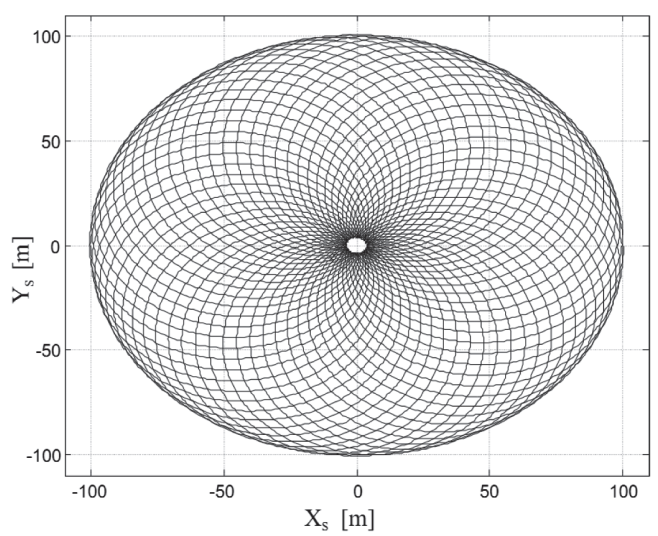

Fig. 3. Scan of the air space by the optoelectronic system of the seeker in its first mode of operation

Angles of rotation and their order are as follows: $\psi$ is the angle of rotation $O X_{C Z} Y_{C Z} Z_{C Z}$ in relation to $O X_{P} Y_{P} Z_{P}$ around axis $Z_{C Z}$;

$\vartheta$ - angle of rotation $O X_{C W} Y_{C W} Z_{C W}$ in relation to $O X_{C Z} Y_{C Z} Z_{C Z}$ around axis $X_{C W}$;

$\phi$ - angle of rotation $O X_{R} Y_{R} Z_{R}$ in relation to $O X_{C W} Y_{C W} Z_{C W}$ around axis $Y_{R}$.

Angles $\psi, \vartheta, \varphi$ specify the location of the gyroscope rotor in relation to the system of coordinates $O X_{P} Y_{P} Z_{P}$. The seeker axis motion can take place under the influence of moments of external forces $M_{Z}$ and $M_{W}$, coming from angular motions of the missile deck and determined with the use of angular velocities $\omega_{x_{P}}, \omega_{y_{P}}, \omega_{z_{P}}$, causing its rotation around individual axes of the system $O X_{P} Y_{P} Z_{P}$ with respective angles $\alpha_{x_{P}} \alpha_{y_{P}} \alpha_{z_{P}}$ and under the influence of moments $M_{S 1}$ and $M_{S 2}$, generated by the controlling motors.
The equations of gyroscope motion have been introduced based on the adopted physical model using the Lagrange equations of the second kind (Awrejcewicz, Koruba 2012; Chatys, Koruba 2005). They employed equations are as follows:

$$
\begin{aligned}
& J_{x_{2}} \frac{d}{d t} \omega_{x_{2}}+J_{x_{3}} \frac{d}{d t} \omega_{x_{2}}+ \\
& -\left(J_{y_{2}}-J_{z_{2}}-J_{z_{3}}\right) \omega_{y_{2}} \omega_{z_{2}}+; \\
& -J_{y_{3}} \omega_{y_{3}} \omega_{z_{2}}=M_{W}-M_{T W} \\
& J_{z_{1}} \frac{d}{d t} \omega_{z_{1}}+J_{y_{2}} \frac{d}{d t}\left(\omega_{y_{2}} \sin \vartheta\right)+ \\
& +J_{z_{2}} \frac{d}{d t}\left(\omega_{z_{2}} \cos \vartheta\right)+J_{y_{3}} \frac{d}{d t}\left(\omega_{y_{3}} \sin \vartheta\right)+ \\
& +J_{z_{3}} \frac{d}{d t}\left(\omega_{z_{2}} \cos \vartheta\right)-\left(J_{x_{1}}-J_{y_{1}}\right) \omega_{x_{1}} \omega_{y_{1}}+ \\
& -\left(J_{x_{2}}+J_{x_{3}}\right) \omega_{x_{2}} \omega_{y_{1}}+J_{y_{2}} \omega_{y_{2}} \omega_{x_{1}} \cos \vartheta+ \\
& -\left(J_{z_{2}}+J_{z_{3}}\right) \omega_{z_{2}} \omega_{x_{1}} \sin \vartheta+J_{y_{3}} \omega_{y_{3}} \omega_{x_{1}} \cos \vartheta= \\
& =M_{Z}-M_{T Z} \\
& J_{y_{3}} \frac{d}{d t}\left(\omega_{y_{2}}+\dot{\Phi}\right)=M_{R}-M_{T R},
\end{aligned}
$$

where: $J_{x_{C Z}}, J_{y_{C Z}}, J_{z_{C Z}}$ indicate moments of inertia of the complete outer housing; $J_{x_{C W}}, J_{y_{C W}}, J_{z_{C W}}$ indicate moments of inertia of the complete inner housing; $J_{x_{R}}, J_{y_{R}}, J_{z_{R}}$ - moments of rotor inertia; $\vec{\omega}_{P}\left(\omega_{x_{P}}, \omega_{y_{P}}, \omega_{z_{P}}\right)^{-}$missile angular velocity; $\vec{M}_{Z}-$ moment of missile forces interacting on the outer housing; $\vec{M}_{W}$ - moment of forces of the outer housing interacting on the inner housing; $\vec{M}_{R}$ - moment of forces of the inner housing interacting on the rotor; $\vec{M}_{T R}-$ moment of friction forces in rotor bearings and aerodynamic resistance; $\vec{M}_{T W}=c_{w} \dot{\vartheta}, \vec{M}_{T Z}=c_{z} \dot{\psi}$ - moments of friction forces in the bearings of respectively inner and outer housing; $c_{w}, c_{z}$ - friction coefficients in the bearing of inner and outer housing.

Angular velocities of individual seeker housings are as follows:

$$
\begin{aligned}
& \omega_{x_{C Z}}=\omega_{x_{P}} \cos \psi+\omega_{y_{P}} \sin \psi ; \\
& \omega_{y_{C Z}}=-\omega_{x_{P}} \sin \psi+\omega_{y_{P}} \cos \psi ; \\
& \omega_{z_{C Z}}=\dot{\psi}+\omega_{z_{P}} ; \\
& \omega_{x_{C W}}=\omega_{x_{C Z}}+\dot{\vartheta} ; \\
& \omega_{y_{C W}}=\omega_{y_{C Z}} \cos \vartheta+\omega_{z_{C Z}} \sin \vartheta ; \\
& \omega_{z_{C W}}=-\omega_{y_{C Z}} \sin \vartheta+\omega_{z_{C Z}} \cos \vartheta .
\end{aligned}
$$

In order to increase the area of scanned space, the seeker axis is set in the programmed motion, for example on the surface of an unwinding spiral. The control of the motion of the head axis was carried out based on the method described in (Osiecki, Stefański 2003, 2008; Stefański 2004). The presented method of controlling the motion of the axis of the designed target seeker uses 
phase trajectories of control deviations. This method involves switching, with the use of control signals $u$ and $v$, control moments, constant in terms of value, at the appropriate points of phase surface. The switching should bring the control deviations to zero. During this control phase, angles $\vartheta_{Z}, \psi_{Z}$ determine the set (desired) motion which should be made by the axis of the scanning head.

The converted equations of motion of the seeker $(1 \mathrm{a}-\mathrm{c})$ will be written in the following form:

$$
\begin{gathered}
\ddot{\vartheta}=\frac{M_{S 1} \cdot u-M_{T W}-\left(J_{x_{2}}+J_{x_{3}}\right) \dot{\omega}_{x_{1}}}{J_{x_{2}}+J_{x_{3}}}+ \\
+\frac{\left(J_{y_{2}}-J_{z_{2}}-J_{z_{3}}\right) \omega_{y_{2}} \omega_{z_{2}}+J_{y_{3}} n \omega_{z_{2}}}{J_{x_{2}}+J_{x_{3}}} \\
\ddot{\psi}=\frac{M_{S 2} \cdot v-M_{T Z}}{J_{z_{1}}+J_{z_{2}}+J_{z_{3}}+\left(J_{y_{2}}-J_{z_{2}}-J_{z_{3}}\right) \sin ^{2} \vartheta}+ \\
-\frac{\left[J_{z_{1}}+J_{z_{2}}+J_{z_{3}}+\left(J_{y_{2}}-J_{z_{2}}-J_{z_{3}}\right) \sin ^{2} \vartheta\right] \dot{\omega}_{z}}{J_{z_{1}}+J_{z_{2}}+J_{z_{3}}+\left(J_{y_{2}}-J_{z_{2}}-J_{z_{3}}\right) \sin ^{2} \vartheta}+ \\
-\frac{0.5\left(J_{y_{2}}-J_{z_{2}}-J_{z_{3}}\right) \sin 2 \vartheta\left(\omega_{z_{1}} \dot{\vartheta}+\dot{\omega}_{y_{1}}\right)}{J_{z_{1}}+J_{z_{2}}+J_{z_{3}}+\left(J_{y_{2}}-J_{z_{2}}-J_{z_{3}}\right) \sin ^{2} \vartheta}+ \\
+\frac{\left[J_{z_{2}}+J_{z_{3}}-\left(J_{y_{2}}-J_{z_{2}}-J_{z_{3}}\right) \sin ^{2} \vartheta\right] \omega_{y_{1}} \dot{\vartheta}}{J_{z_{1}}+J_{z_{2}}+J_{z_{3}}+\left(J_{y_{2}}-J_{z_{2}}-J_{z_{3}}\right) \sin ^{2} \vartheta}+ \\
+\frac{\left(J_{z_{2}}+J_{z_{3}}\right) \omega_{z_{2}} \omega_{x_{2}} \cos \vartheta-J_{y_{2}} \omega_{y_{2}} \omega_{x_{2}} \cos \vartheta}{J_{z_{1}}+J_{z_{2}}+J_{z_{3}}+\left(J_{y_{2}}-J_{z_{2}}-J_{z_{3}}\right) \sin ^{2} \vartheta}+ \\
+\frac{J_{y_{3}} n \omega_{x_{2}} \cos \vartheta+\left(J_{x_{1}}-J_{y_{1}}\right) \omega_{x_{1}} \omega_{y_{1}}}{J_{z_{1}}+J_{z_{2}}+J_{z_{3}}+\left(J_{y_{2}}-J_{z_{2}}-J_{z_{3}}\right) \sin ^{2} \vartheta}+\left(J_{x_{2}}+J_{x_{3}}\right) \omega_{x_{2}} \omega_{y_{1}} \\
+\frac{J_{z_{1}}+J_{z_{2}}+J_{z_{3}}+\left(J_{y_{2}}-J_{z_{2}}-J_{z_{3}}\right) \sin ^{2} \vartheta}{}+
\end{gathered}
$$

where $M_{S 1}=M_{S 2}=$ const indicates control moments; and $n=\dot{\Phi}$ indicates angular velocity of the rotor $[\mathrm{rad} / \mathrm{s}]$.

Control signals $u$ and $v$ have been formulated as follows:

$$
\begin{aligned}
& u=-\operatorname{sgn}\left(e_{1}\right) ; \\
& v=-\operatorname{sgn}\left(e_{2}\right),
\end{aligned}
$$

where $e_{1}$ and $e_{2}$ indicate control deviations which have the form of:

$$
\begin{aligned}
& e_{1}=\vartheta-\vartheta_{Z} \\
& e_{2}=\psi-\psi_{Z} .
\end{aligned}
$$

\section{Presentation of analysis results}

Numerical research was conducted for the first operation mode of the designed scanning seeker intended for close-range surface-to-air missiles.

\subsection{Numerical data of the optical target seeker}

The numerical data obtained from the optical target seeker were as follows:

Rotary velocity of the rotor: $n=600[\mathrm{rad} / \mathrm{s}]$.

Friction coefficients of inner and outer housing in the bearing: $c_{w}=c_{z}=0.05$ [Nms].

Maximum torque of controlling motors: $M_{S 1 \text { max }}=M_{S 2 \max }=0.8[\mathrm{Nm}]$.

Moments of rotor inertia: $J_{x_{R}}=0.00114143\left[\mathrm{kgm}^{2}\right]$; $J_{y_{R}}=0.00157911\left[\mathrm{kgm}^{2}\right] ; J_{z_{R}}=0.00158234\left[\mathrm{kgm}^{2}\right]$. Moments of complete inner housing inertia: $J_{x C W}=0.0016663\left[\mathrm{kgm}^{2}\right] ; \quad J_{y C W}=0.0011666\left[\mathrm{kgm}^{2}\right] ;$ $J_{z C W}=0.0011463\left[\mathrm{kgm}^{2}\right]$.

Moments of complete outer housing inertia: $J_{x C Z}=0.0003383\left[\mathrm{kgm}^{2}\right] ; \quad J_{y_{C Z}}=0.0002213\left[\mathrm{kgm}^{2}\right] ;$ $J_{z C Z}=0.0002583\left[\mathrm{kgm}^{2}\right]$.

\subsection{Numerical simulation results}

Figure 4 presents the direct detection of an air target moving with the velocity of $200[\mathrm{~m} / \mathrm{s}]$, which is $2000[\mathrm{~m}]$ away from the firing position. The time required for detecting the target amounted to 0.144 [s]. The set angular coordinates of the location of the detected target in relation to the seeker axis are as follows: $\beta_{X}=-0.913$ [deg], $\beta_{\gamma}=-1.573$ [deg].

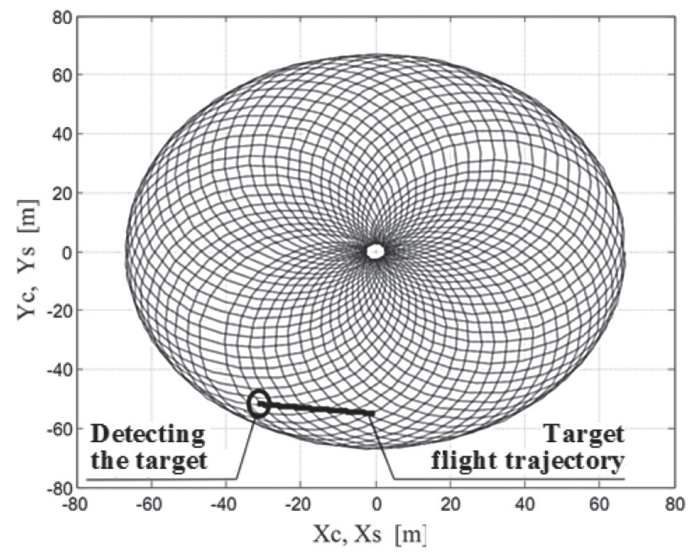

Fig. 4. Direct detection of air target

If the target is not detected directly through the optoelectronic system of the seeker, the optical axis of the head will be automatically set according to the programmed motion and, as a result, the scope of scanned space will be increased.

Control of the seeker axis was realized by setting its motion on the surface of a circular cone and on the surface of the unwinding coil. The torques of the controlling motors then assume a constant value of $0.8[\mathrm{Nm}]$. 
Figures 5-10 present the results of digital simulation of the scanning head axis control by setting its motion on the surface of a circular cone at the same time taking into consideration air space scanning by the optoelectronic system of the device. The target was moving at a $200[\mathrm{~m} / \mathrm{s}]$ velocity and was 2000 [m] away from the firing position. Figure 5 presents the diagram of the set angular velocity of the seeker axis moving on the surface of a circular cone. In the initial phase of control, the scanning head axis accelerates until the moment it achieves the set angular velocity amounting to $360[\mathrm{deg} / \mathrm{s}]$. In the further phase of control, the angular velocity of the axis is maintained at a constant level of 360 [deg/s].

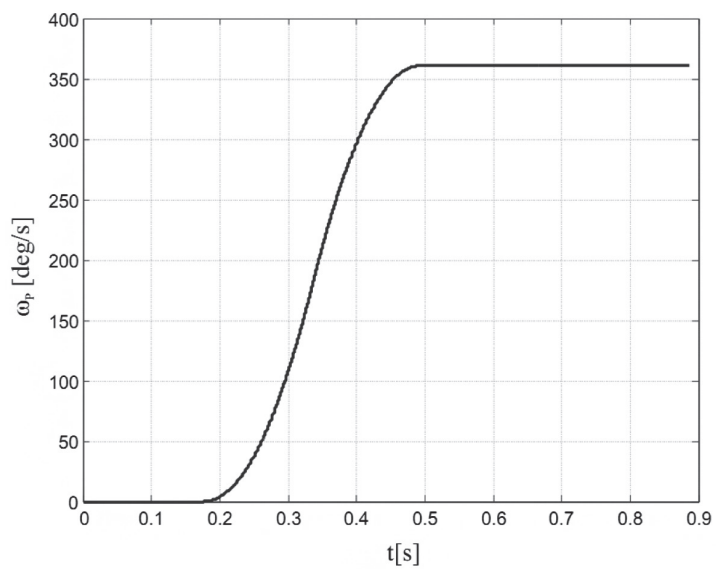

Fig. 5. The set angular velocity of circling around a circular cone by the seeker axis

Figures 6 and 7 present the trajectory that was set and is followed by the seeker axis, while figure 8 presents air space search performed by the seeker and target detection.

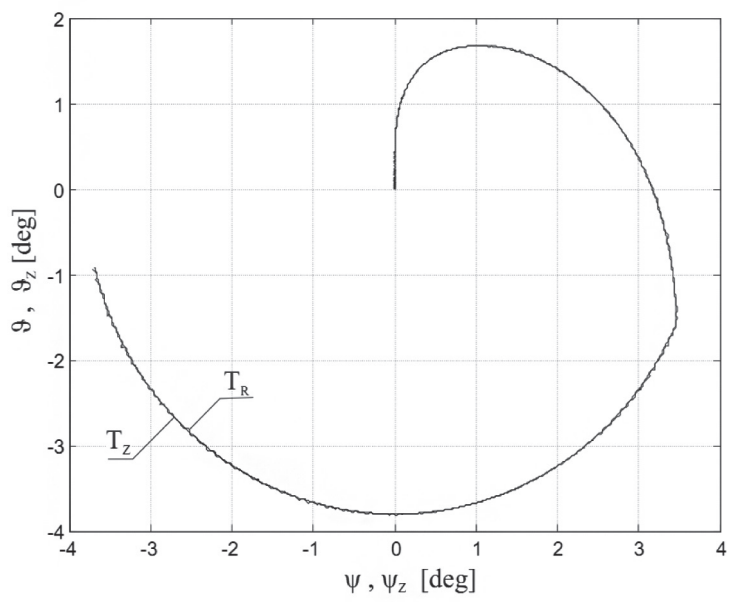

Fig. 6. The trajectory of the set $T_{Z}$ and the actual $T_{R}$ motion of the seeker axis

The time for target detection amounted to 0.887 [s], while the set angular coordinates of detected target location were $\sigma=-4.897$ [deg] and $\varepsilon=-1.474$ [deg]. Angles $\varepsilon$ and $\sigma$ determine the current location of line-of-sight in space, and are determined systematically by the optoelectronic system of the scanning head. In figure 4 the angles are equal respectively $\beta_{X}=\sigma, \beta_{Y}=\varepsilon$ because the seeker axis overlapped with the axis of the missile.

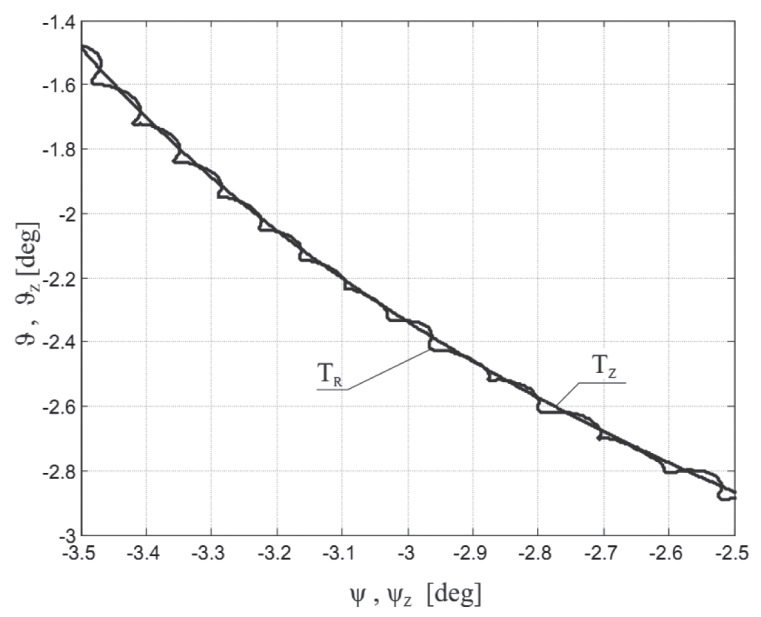

Fig. 7. An enlarged section of the set $T_{Z}$ trajectory and the actual motion $T_{R}$ of the seeker axis

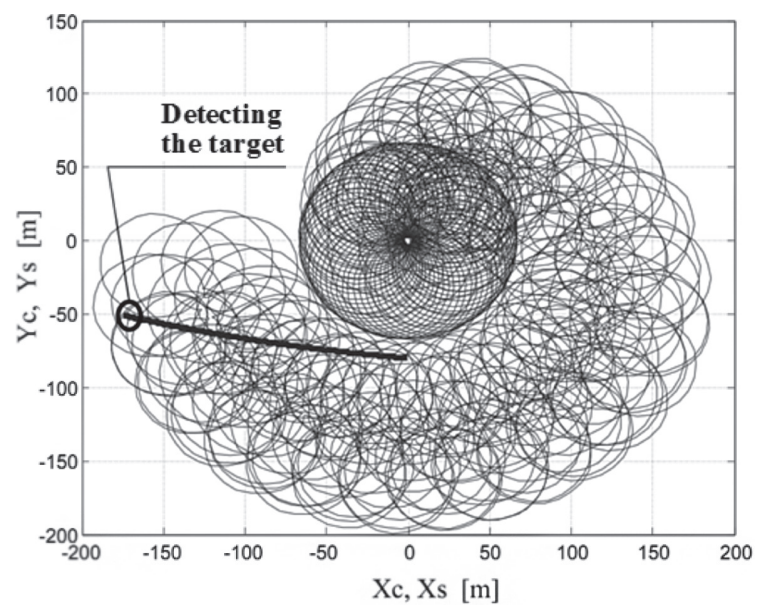

Fig. 8. Air space search by setting the seeker axis into programmed motion on the surface of the circular cone and detection of air target

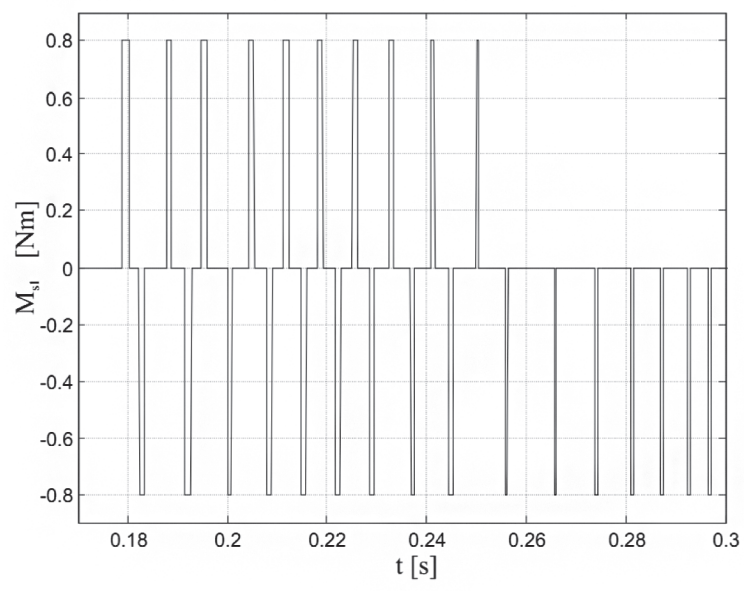

Fig. 9. The control moment of seeker inner housing 


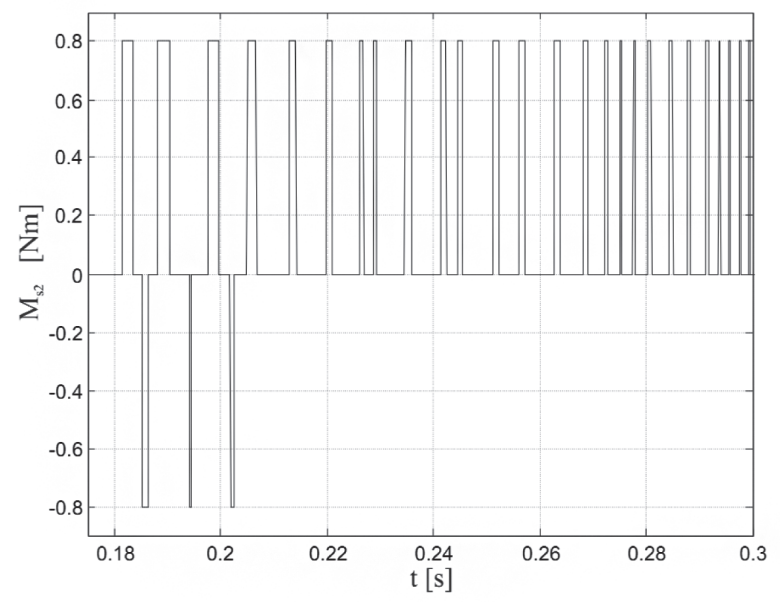

Fig. 10. The control moment of seeker outer housing

Figure 11 presents the diagram of angular velocity set for the seeker axis in its motion on the surface of the unwinding spiral. At the same time scanning of air space by the device's optoelectronic system is considered. The target was moving with the velocity of $30[\mathrm{~m} / \mathrm{s}]$ and was $1500[\mathrm{~m}]$ away from the firing position. In the initial phase of control, the head axis accelerates until it achieves the set angular velocity which amounts to $180[\mathrm{deg} / \mathrm{s}]$. In the further phase of control, the angular velocity of the axis is maintained at a constant level of $180[\mathrm{deg} / \mathrm{s}]$. Figure 12 presents the trajectory set and carried out by the seeker axis, while figures 13-16 present the rotation set and carried out by individual housings of the seeker. The search of air space by the seeker and detection of the target is shown in figure 17. The time required for target detection amounted to 8 [s], while the set angular coordinates of the location of the detected target were $\sigma=0.486$ [deg] and $\varepsilon=14.89$ [deg].

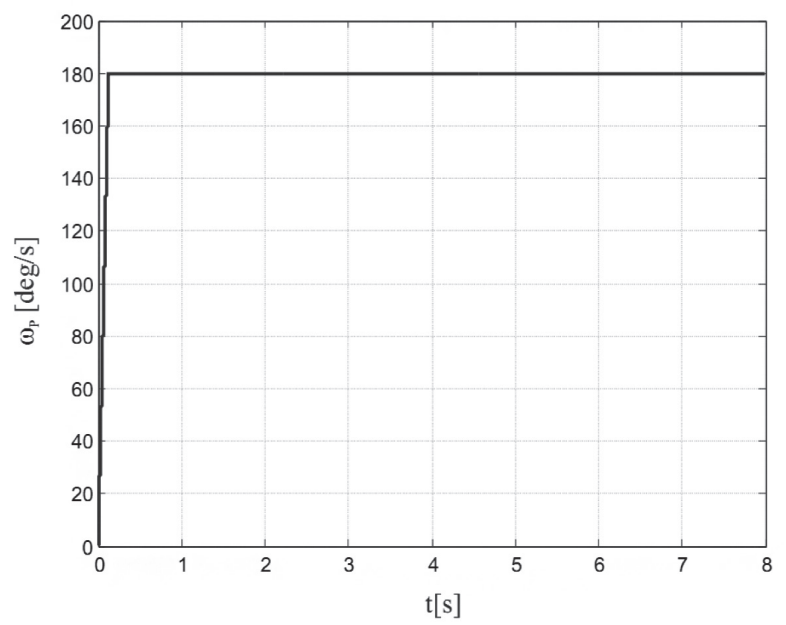

Fig. 11. The set angular velocity of the seeker axis when in motion on the surface of an unwinding spiral

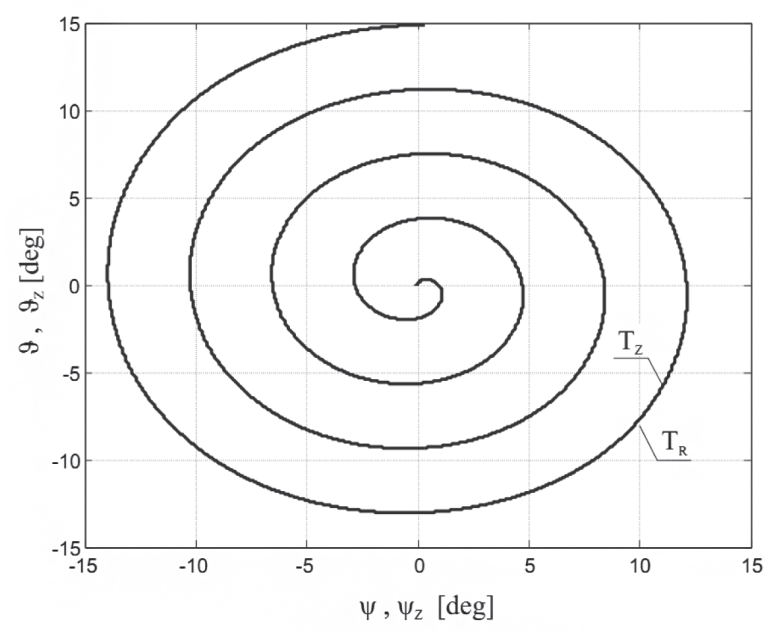

Fig. 12. The trajectory of the set $T_{Z}$ and the actual motion $T_{R}$ of the seeker axis

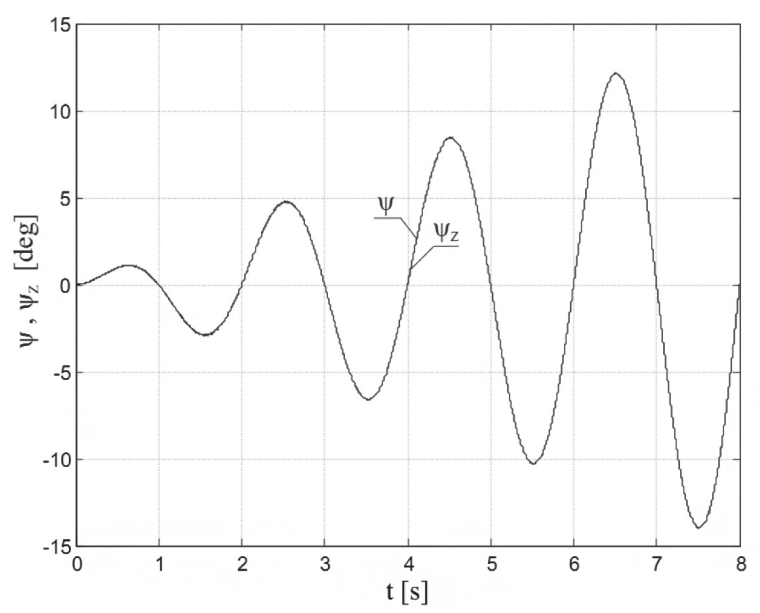

Fig. 13. The desired and actual rotation of the outer housing around the axis $Z_{C Z}$

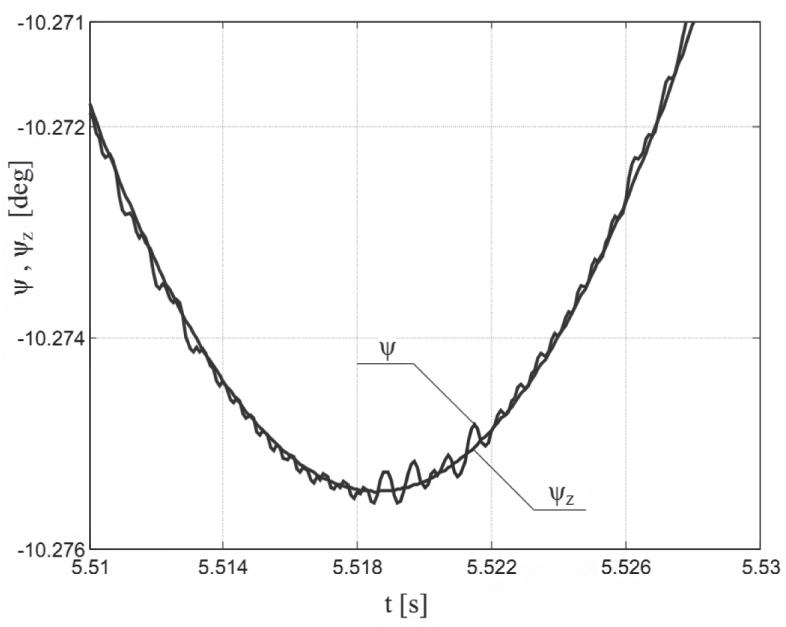

Fig. 14. An enlarged fragment of the diagram showing the desired and actual rotation of the outer housing around the axis $Z_{C Z}$ 


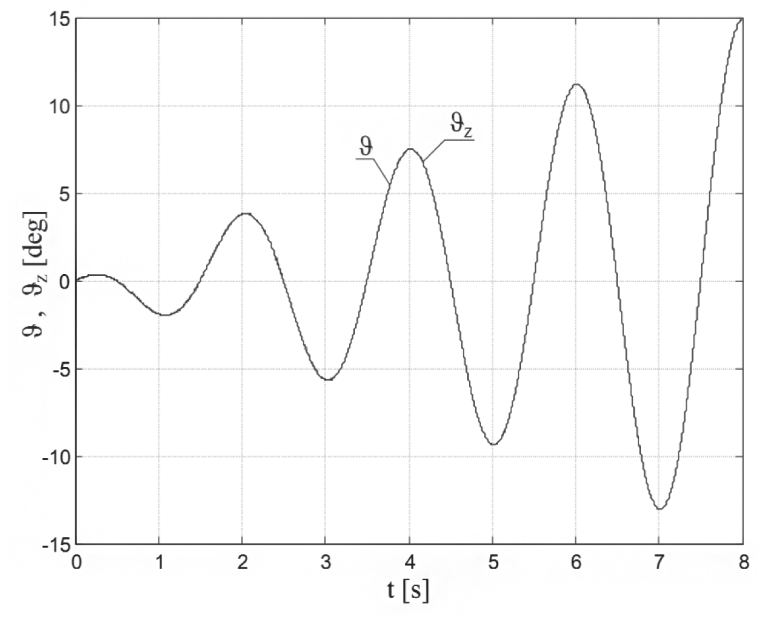

Fig. 15. The desired and actual rotation of the inner housing around the axis $X_{C W}$

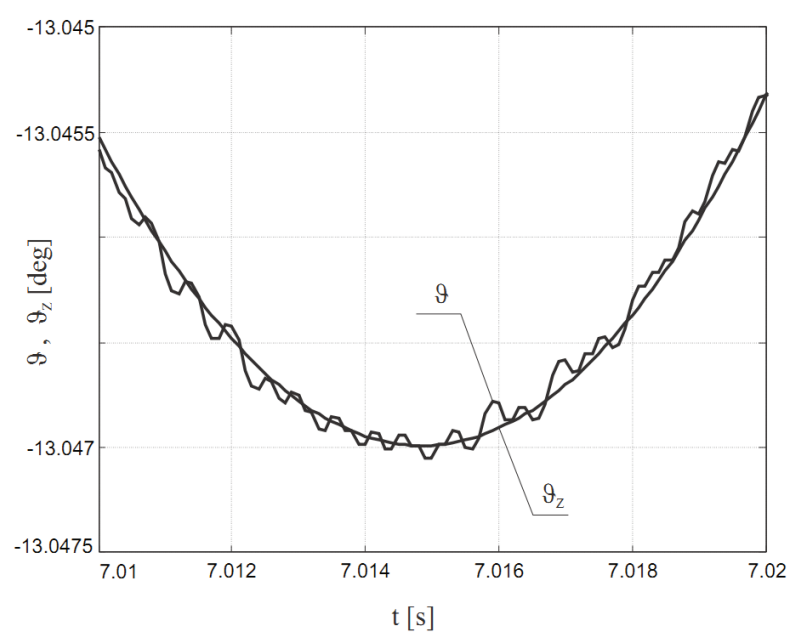

Fig. 16. An enlarged fragment of the diagram showing the desired and actual rotation of the inner housing around the axis $X_{C W}$

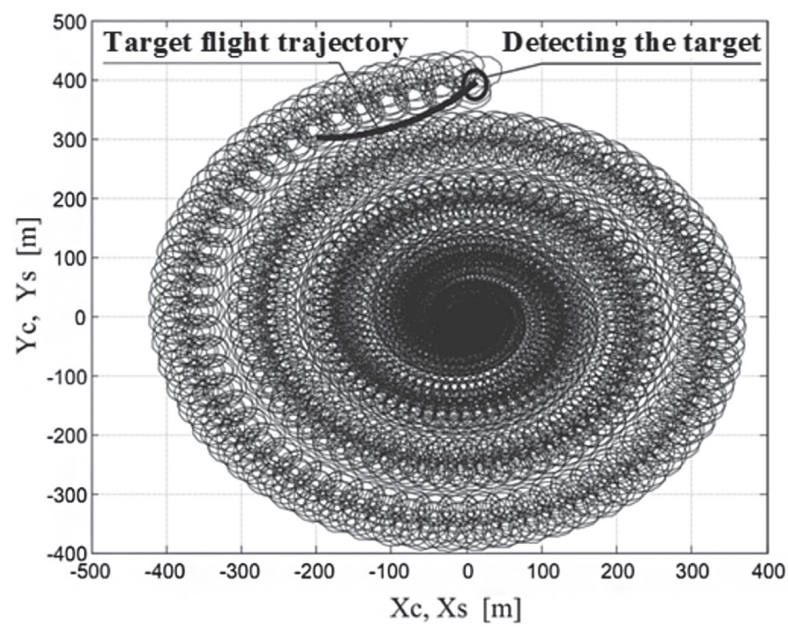

Fig. 17. The search of air space by setting the seeker axis into a programmed motion on the surface of the unwinding spiral and detection of air target

\section{Review of analysis results}

From the conducted numerical simulations it appears that the control of the designed target seeker with the use of electrical controlling motors with constant torques is done with sufficient precision for self-guidance. The use of the above indicated motors significantly simplifies the whole system of controlling the head. Due to this solution, it is possible to replace the voltage controller with a very simple and fast led or semi-conductor system. The task of such a system is only limited to generating control signals in the form of electrical impulses of the values: 1,0 or -1 . The control signals are generated on the basis of control deviations, which are systematically determined by the fibre-optic sensors of angular displacements installed in the device. From the analysis of the course of control moments presented in figures 9,10,18 and 19, it appears that the frequency of controlling impulses does not exceed $10[\mathrm{kHz}]$. This proves the technical feasibility of the method of seeker axis control presented in the article as semi-conductor switches currently present in the market are able to generate control impulses with such a frequency.

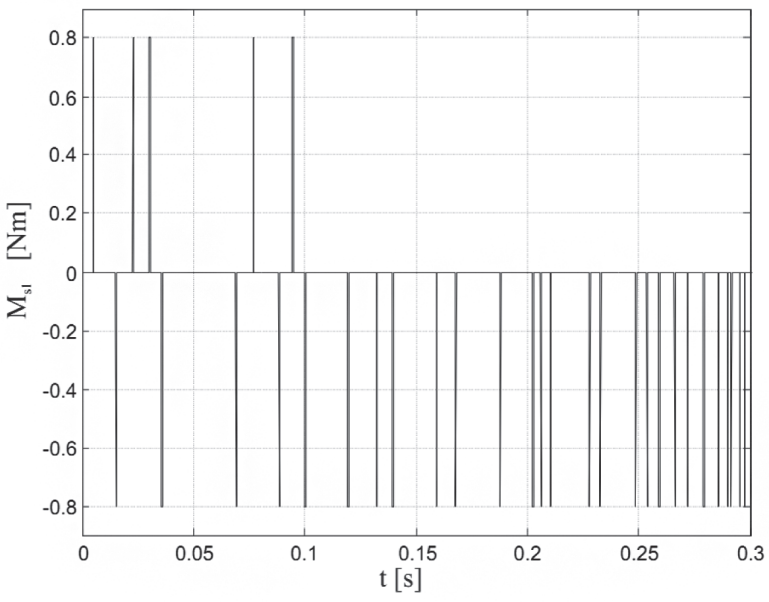

Fig. 18. The control moment the seeker inner housing

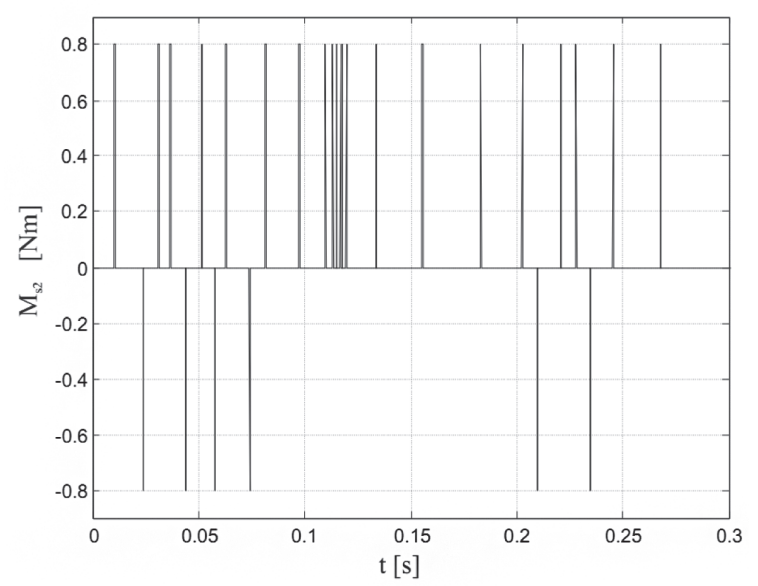

Fig. 19. The control moment the seeker outer housing 


\section{References}

Anderson, D.; Borchard, J. F.; Wellman, W. 2010. Optical System for Aide Field of View Staring Infrared Sensor Having Improved Optical Symmetry. Europen Patent EP 1618358 B1, 2010.

Awrejcewicz, J.; Koruba, Z. 2012. Classical Mechanics. Applied Mechanics and Mechatronics. Vol. 30. New York, Heidelberg, Dordrecht, London: Springer. $250 \mathrm{p}$. http://dx.doi.org/10.1007/978-1-4614-3740-6

Barenz, J.; Baumann, R.; Eckhardt, R., et al. 2012. Verfahren zum Steuern Eines Lenkflugkörpers und Suchkopf für Einen Lenkflugkörper. Deutsches Patent - und Markenamt DE 102010055493 A1.

Chatys, R.; Koruba, Z. 2005. Gyroscope-based control and stabilization of unmanned aerial mini-vehicle (mini-UAV), Aviation 9(2): 10-16.

http://dx.doi.org/10.1080/16487788.2005.9635898

Gapiński, D. 2008. The Patent of the Optical Scanning Head for a Homing Missile. Patent Office of the Republic of Poland, PL 199721 B1 (application number 375907).

Rueger, R.; Zoz, J. 2012. Infrared Seeker Head. United States Patent US 2012/0248238 A1.

Osiecki, J. W.; Stefański, K. 2003. Controlling of the course and bearing indicator on the basis of phase trajectories, in Kitowski, Z.; Lisowski, J. (Eds.). Automation and Use of Control and Communications Systems. Vol. 2. Gdynia, 421-428 (in Polish).

Osiecki, J. W.; Stefański, K. 2008. On a method of target detection and tracking used in air defence, Journal of Theoretical and Applied Mechanics 46(4): 909-916.

Stefański, K. 2004. A system for the scanning of limited space and automatic determination of target bearings, in Materials of the III Scientific Conference "Directing the fire of air (anti-aircraft) defence systems", 25-27 May, 2004, Koszalin. 385-394 (in Polish). 